\title{
Теплоотводящие электроизолирующие платы для фотоэлектрических преобразователей концентрированного солнечного излучения
}

\author{
( Н.Ю. Давидюк, А.В. Андреева, Д.А. Малевский, П.В. Покровский, Н.А. Садчиков, \\ А.В. Чекалин
}

Физико-технический институт им. А.Ф. Иоффре РАН, Санкт-Петербург, Россия

ฯ E-mail: chekalin@mail.ioffe.ru

Поступило в Редакцию 10 февраля 2020 г.

В окончательной редакции 10 февраля 2020 г.

Принято к публикации 11 февраля 2020 г.

\begin{abstract}
Представлены результаты исследований характеристик теплоотводящих электроизолирующих плат разной конструкции, изготовленных на основе теплопроводящих керамик $\mathrm{AlN}$ и $\mathrm{Al}_{2} \mathrm{O}_{3}$, а также алюмооксидных плат на базе алюминиевых пластин. Теплофизические параметры теплоотводящих плат оценивались путем измерения температуры $p-n$-переходов фотоэлектрических преобразователей, установленных на платы, при подаче на них тепловой нагрузки. Установлено, что минимальные значения температуры перегрева $p-n$ переходов $45^{\circ} \mathrm{C}$ при подводимой тепловой мощности, равной $13 \mathrm{~W}$, наблюдались при их монтаже на керамику AlN. Величина перегрева $p-n$-переходов при монтаже на керамику $\mathrm{Al}_{2} \mathrm{O}_{3}$ составила $49^{\circ} \mathrm{C}$, а при монтаже на алюмооксидное основание - порядка $70^{\circ} \mathrm{C}$.
\end{abstract}

Ключевые слова: солнечные элементы, $p-n$-переход, измерение температуры, материал теплоотводов, концентраторные фотоэлектрические преобразователи, тепловые характеристики.

DOI: 10.21883/PJTF.2020.09.49369.18239

Во многих областях силовой электроники при работе электронных компонентов с высоким уровнем тепловыделения ставится задача эффективного отвода тепла с помощью теплоотводящих электроизолирующих плат [1]. Известно, что эффективность преобразования солнечного излучения в электроэнергию, в том числе в концентраторных фотоэлектрических модулях (КФЭМ), уменьшается с увеличением температуры $p-n$-переходов фотоэлектрических преобразователей (ФЭП) [2]. В КФЭМ для эффективного отвода тепла от ФЭП и обеспечения электроизоляции при установке нескольких ФЭП на электрогенерирующих панелях модулей могут также эффективно использоваться электроизолирующие теплоотводящие платы.

Выявление тепловых характеристик теплоотводящих плат может осуществляться путем измерения температуры $p-n$-переходов фотоэлектрических преобразователей при подаче на ФЭП определенной тепловой нагрузки. В настоящей работе проведены исследования эффективности отвода тепла от ФЭП при использовании теплоотводящих электроизолирующих плат разной конструкции.

Разработанный для экспериментов КФЭМ включает линзу Френеля размером $12 \times 12 \mathrm{~cm}$ и электрогенерирующую панель, включающую основание из алюминия размером $14 \times 14 \mathrm{~cm}$ с платой, закрепляемой в центре основания с помощью теплопроводящей пасты „Overcool ТC-200“ с теплопроводностью $3.8 \mathrm{~W} /(\mathrm{m} \cdot \mathrm{K})$. На верхнюю поверхность платы в ее центре напаивался ФЭП размером $5.5 \times 6 \mathrm{~mm}$.

Были исследованы четыре типа теплоотводящих электроизолирующих плат: два типа плат на основе керамик
$\mathrm{AlN}$ и $\mathrm{Al}_{2} \mathrm{O}_{3}$ и два типа алюмооксидных плат на основе алюминиевых пластин разного размера с диэлектрическими слоями оксида алюминия. На рис. 1 представлены конструкции плат с указанием материалов и толщин слоев плат.

Исследование тепловых характеристик образцов ФЭП на платах в натурных условиях при облучении концентрированным солнечным излучением затруднено, поскольку условия измерения не являются стабильными вследствие изменений как интенсивности освещения, так и условий теплоотвода, зависящих от направления и скорости ветра [3]. Поэтому исследования теплофизических

\begin{tabular}{|c|c|c|}
\hline \multirow[t]{2}{*}{$a$} & $b$ & $c$ \\
\hline & $\mathrm{Au}, 0.1 \mu \mathrm{m}$ & $\mathrm{Au}, 0.1 \mu \mathrm{m}$ \\
\hline $\mathrm{Au}, 0.1 \mu \mathrm{m}$ & \multirow{2}{*}{$\mathrm{Cu}, 300 \mu \mathrm{m}$} & \multirow{2}{*}{$\mathrm{Cu}, 70 \mu \mathrm{m}$} \\
\hline $\mathrm{Cu}, 125 \mu \mathrm{m}$ & & \\
\hline & \multirow[b]{2}{*}{$\begin{array}{c}\text { Ceramics } \mathrm{Al}_{2} \mathrm{O}_{3}, \\
380 \mu \mathrm{m}\end{array}$} & Al-oxide, $70 \mu \mathrm{m}$ \\
\hline $\begin{array}{c}\text { Ceramics AlN, } \\
380 \mu \mathrm{m}\end{array}$ & & \multirow{2}{*}{$\mathrm{Al}, 1500 \mu \mathrm{m}$} \\
\hline $\mathrm{Cu}, 125 \mu \mathrm{m}$ & \multirow[t]{2}{*}{$\mathrm{Cu}, 300 \mu \mathrm{m}$} & \\
\hline \multirow[t]{2}{*}{$\mathrm{Au}, 0.1 \mu \mathrm{m}$} & & \multirow[b]{2}{*}{ Al-oxide, $70 \mu \mathrm{m}$} \\
\hline & $\mathrm{Au}, 0.1 \mu \mathrm{m}$ & \\
\hline
\end{tabular}

Рис. 1. Структуры теплоотводящих электроизолирующих плат на основе керамики $\mathrm{AlN}(a)$ и $\mathrm{Al}_{2} \mathrm{O}_{3}(b)$ и пластин с диэлектрическими слоями оксида алюминия $(c)$. 
характеристик теплоотводящих плат осуществлялись в помещении в затемненных условиях.

Была использована методика определения величины перегрева $p-n$-перехода ФЭП относительно комнатной температуры при пропускании прямого тока [4]. При этом индикатором температуры ФЭП служили значения прямого падения напряжения на $p-n$-переходе [5].

Согласно разработанной методике, исследуемый КФЭМ с установленной теплоотводящей электроизолирующей платой и напаянным фотопреобразователем был помещен в термостат, температура в котором менялась от комнатной до $100^{\circ} \mathrm{C}$. При разных фиксированных значениях температуры термостата были измерены вольтамперные характеристики ФЭП при подаче тока в режиме одиночных импульсов длительностью $200 \mu \mathrm{s}$, после чего были рассчитаны значения температурного коэффициента $\beta$ изменения напряжения на $p-n$-переходе при заданной плотности тока для исследуемых ФЭП.

Затем при комнатной температуре через контакты исследуемого ФЭП пропускался постоянный ток в прямом направлении. При этом выделяемая в $p-n$-переходе электрическая мощность приводила к разогреву ФЭП. По истечении времени, необходимого для перехода всей системы в стационарное температурное состояние, производилось размыкание контактов с помощью электронного коммутатора и за время уменьшения тока до нуля осуществлялась регистрация вольт-амперной характеристики ФЭП в разогретом состоянии.

Расчет перегрева $(\Delta T) p-n$-переходов относительно температуры окружающей среды для разных значений плотности тока осуществлялся по формуле

$$
\Delta T_{p-n}=\frac{V_{h o t}-V_{a m b}}{\beta \cdot 10^{-3}},
$$

где $\beta[-\mathrm{mV} / \mathrm{K}]$ - температурный коэффициент изменения напряжения на $p-n$-переходе при заданной плотности тока; $V_{h o t}[\mathrm{~V}]$ и $V_{a m b}[\mathrm{~V}]$ - значения напряжений на $p-n$-переходе при установившейся температуре в нагретом состоянии и при температуре окружающей среды соответственно.

На рис. 2 приведены температурные характеристики четырех образцов ФЭП, напаянных на теплоотводящие электроизолирующие платы четырех разных конструкций: две платы размером $2.2 \times 2.2 \mathrm{~cm}$ на основе теплопроводящих керамик (зависимости 1 и 2) и две алюмооксидные платы разного размера $3 \times 3 \mathrm{~cm}$ (зависимость 3) и $5 \times 5 \mathrm{~cm}$ (зависимость 4 ).

Как видно из приведенных на рис. 2 зависимостей, наименьшие температуры перегрева $p-n$-переходов ФЭП наблюдались при их напайке на теплоотводящие платы на основе керамик $\mathrm{AlN}$ и $\mathrm{Al}_{2} \mathrm{O}_{3}$. При подводимой электрической мощности $13 \mathrm{~W}$ перегрев ФЭП на этих платах составлял $\Delta T=43-49^{\circ} \mathrm{C}$. Относительно низкая эффективность отвода тепла в алюмооксидных платах $\left(\Delta T=68-71^{\circ} \mathrm{C}\right)$ может быть объяснена высокой пористостью и низкой теплопроводностью оксидных слоев на верхней и нижней поверхностях алюминиевой пластины.

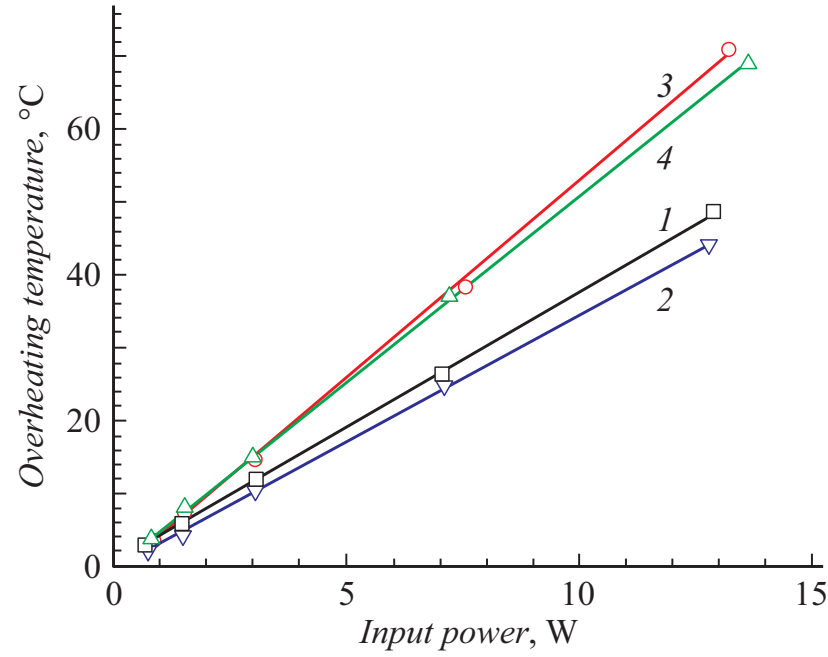

Рис. 2. Зависимость температуры перегрева фотоэлементов от мощности нагрева ФЭП, напаянных на теплоотводящие электроизолирующие платы. 1,2 - на основе теплопроводящих керамик $\mathrm{Al}_{2} \mathrm{O}_{3}$ и $\mathrm{AlN}$ соответственно, 3, 4 - алюмооксидные платы размером $3 \times 3$ и $5 \times 5 \mathrm{~cm}$ соответственно.

При мощности прямого солнечного излучения $850 \mathrm{~W} / \mathrm{m}^{2}$ линза Френеля с КПД $85 \%$ размером $12 \times 12 \mathrm{~cm}$ фокусирует на поверхность ФЭП излучение мощностью $10.4 \mathrm{~W}$. Концентраторный модуль на основе каскадного ФЭП $\mathrm{GaInP} / \mathrm{GaAs} / \mathrm{Ge}$ имеет КПД 30\%. При такой эффективности существенная часть (30\%) тепловой мощности $\left(P_{t}\right)$ излучения, падающего на поверхность ФЭП, отводится в полезную нагрузку, а остальная часть $\left(P_{t} \approx 7 \mathrm{~W}\right)$ превращается в тепло, которое необходимо максимально эффективно отвести от ФЭП. Как видно из рис. 2 , перегрев $\Delta T$ фотоэлектрических преобразователей при такой тепловой мощности составляет $\Delta T \approx 25^{\circ} \mathrm{C}$ при использовании теплоотводящих плат на основе керамик $\mathrm{Al}_{2} \mathrm{O}_{3}$ и $\mathrm{AlN}$ и $\Delta T \approx 36^{\circ} \mathrm{C}$ при использовании алюмооксидных плат.

На рис. 3 представлены расчетные распределения температуры вдоль поверхности электрогенерирующих панелей, включающих ФЭП и плату, размещенную в центре алюминиевого основания: с алюмооксидной теплоотводящей платой (рис. 1, c и рис. 3 , распределение 1 ) и с платой на основе керамики $\mathrm{Al}_{2} \mathrm{O}_{3}$ (рис. $1, b$ и рис. 3 , распределение 2). В расчетах были использованы следующие исходные параметры: температура окружающей среды $25^{\circ} \mathrm{C}$; выделяемая в ФЭП тепловая мощность $P_{t}=7 \mathrm{~W}$; теплопроводность меди $390 \mathrm{~W} /(\mathrm{m} \cdot \mathrm{K})$; теплопроводность алюминия $200 \mathrm{~W} /(\mathrm{m} \cdot \mathrm{K})$; теплопроводность керамики $\mathrm{Al}_{2} \mathrm{O}_{3} 30 \mathrm{~W} /(\mathrm{m} \cdot \mathrm{K})$. Температуры крайних точек алюминиевого основания, введенные в расчет, были измерены с помощью терморезисторов.

Типичное значение относительного коэффициента температурного снижения КПД концентраторных фотоэлектрических модулей (с КПД $\sim 30 \%$ при $25^{\circ} \mathrm{C}$ ) на основе каскадных ФЭП составляет $K_{t} \approx-0.074 \% / \mathrm{K}[6]$ 


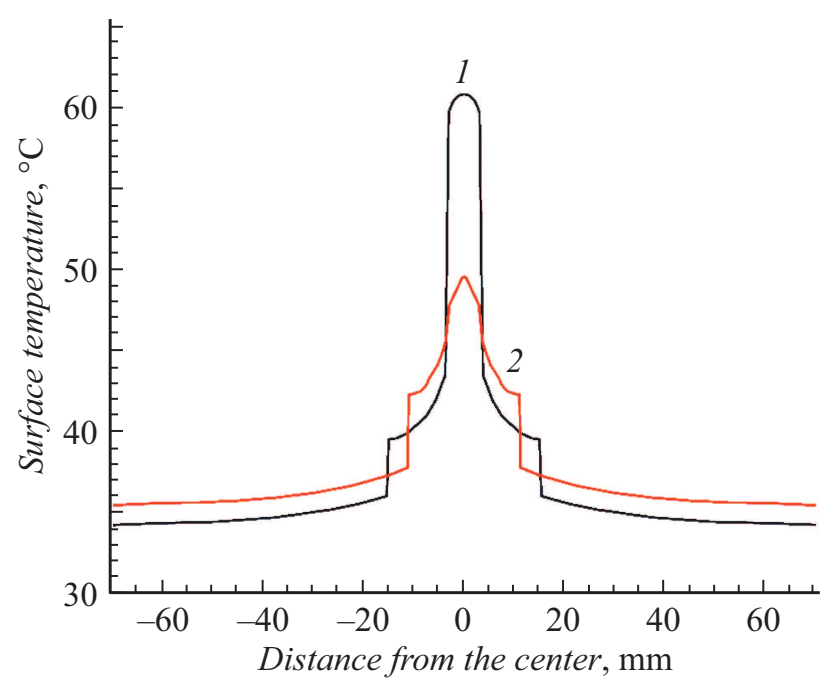

Рис. 3. Расчетные распределения температуры вдоль поверхности двух электрогенерирующих сборок ФЭП + плата + Alоснование размером $12 \times 12 \mathrm{~cm}$ с теплопроводящими платами двух типов: алюмооксидная плата размером $3 \times 3 \mathrm{~cm}(1)$ и плата размером $2.2 \times 2.2 \mathrm{~cm}$ на основе керамики $\mathrm{Al}_{2} \mathrm{O}_{3}(2)$.

при кратности концентрирования солнечного излучения, равной 500 „солнщ“. При величине перегрева $\Delta T=30-45^{\circ} \mathrm{C}$ фотоэлектрического преобразователя в КФЭМ с разработанными теплоотводящими платами снижение КПД фотоэлектрического модуля за счет разогрева составляет величину порядка $1 \%$.

Таким образом, использование в качестве электроизолирующих плат как керамик $\mathrm{AlN}$ и $\mathrm{Al}_{2} \mathrm{O}_{3}$, так и алюмооксида обеспечивает эффективный отвод тепла, выделяющегося в каскадном ФЭП, расположенном в фокусе линзы Френеля размером $12 \times 12 \mathrm{~cm}$.

\section{Финансирование работы}

Исследование выполено за счет гранта Российского научного фонда (проект № 17-79-30035).

\section{Конфликт интересов}

Авторы заявляют, что у них нет конфликта интересов.

\section{Список литературы}

[1] Бечтлофб У., Фихлер Р., Шауэр Й., Шмидер К. // Технологии в электронной промышленности. 2005. № 3. C. $22-24$.

[2] Rumyantsev V.D. Terrestrial concentrator PV systems // Concentrator photovoltaics. Springer Ser. in Optical Sciences. 2016. V. 130. P. $151-174$

[3] Núñez R., Antón I., Askins S., Sala G., Araki K. // AIP Conf. Proc. 2014. V. 1616. P. 144-148.

[4] Rumyantsev V.D., Davidyuk N.Yu., Chekalin A.V., Malevskiy D.A., Pan'chak A.N., Sadchikov N.A., Andreev V.M., Luque A. // IEEE J. Photovolt. 2015. V. 5. N 6. P. 1715-1721.
[5] Kinsey G.S., Hebert P., Barbour K.E., Krut D.D., Cotal H.L., Sherif R.A. // Prog. Photovolt.: Res. Appl. 2008. V. 16. N 6. P. 503-508.

[6] Siefer G., Bett A.W. // Prog. Photovolt.: Res. Appl. 2014. V. 22. N 5. P. 515-524. 